\title{
Single dose ketamine injection affects activation of cells in the nucleus accumbens of prenatally stressed rats
}

\author{
Elif Polat Çorumlu' ${ }^{1}$ Osman Özcan Aydın ${ }^{1}$, Emel Ulupınar ${ }^{1,2}$ \\ ${ }^{1}$ Interdisciplinary Neuroscience Department, Osmangazi University, Eskişehir, Turkey \\ ${ }^{2}$ Department of Anatomy, Faculty of Medicine, Osmangazi University, Eskişebir, Turkey
}

\begin{abstract}
Objectives: The nucleus accumbens (NAc) has recently been implicated in the pathophysiology of depression. In animals displaying depressive-like behavior following chronic stress exposure, glutamatergic transmission increases in the NAc. NMDA receptor antagonist ketamine act as an antidepressant, especially in treatment-resistant cases. In this study, we aimed to investigate the effects of single-dose ketamine application in the activation of cells in the NAc of prenatally stressed rats.

Methods: Sprague-Dawley dams were exposed to immobilization stress during the last week of pregnancy for 3 hours. Male offspring were divided into four groups at postnatal day 40. Prenatal stress and control groups received either a single dose of ketamine (10 mg/kg, i.p.) or same doses of saline injections. Immediate gene activation was stimulated by forced swim for 6 minutes and assessed by c-Fos immunohistochemistry. The total number of activated cells in the core and shell subregions was estimated by optical fractionator method.

Results: The total number of activated cells in the shell subregion significantly decreased in prenatally stressed rats. Ketamine administration reversed their activation level similar to those of control group. Although activation of cells did not change in the core region following prenatal stress, ketamine treatment enhanced the activation of cells in this region both control and prenatally stressed animals.

Conclusion: These results suggest that prenatal stress influences the activation of NAc in a subdivision specific manner, but ketamine treatment could act on both core and shell regions by affecting glutamatergic limbic information that flows from shell to core subregion of the NAC.
\end{abstract}

Keywords: c-Fos; ketamine; nucleus accumbens; prenatal stress; stereology

Anatomy 2017;11(3):115-120 @2017 Turkish Society of Anatomy and Clinical Anatomy (TSACA)

\section{Introduction}

Stressful experiences during pregnancy might lead to diverse consequences including neuroendocrine abnormalities, metabolic disorders, behavioral and cognitive problems in the offspring. ${ }^{[1,2]}$ Prenatal stress (PS) exposure disturbs the brain development of pups by altering expression of stress hormones, neurotransmitters and their receptors, ${ }^{[3,4]}$ activity of several ion channels ${ }^{[5]}$ and synaptic formation. ${ }^{[6]}$ Numerous studies have shown the effects of PS on the limbic structures, such as the hippocampus and the prefrontal cortex, ${ }^{[7,8]}$ whereas relatively little is known about effects on the other limbic structures. The nucleus accum- bens (NAc) is the center of reward mood and motivation, but it has recently been implicated in the pathophysiology of depression especially via dopaminergic and glutamatergic alterations..$^{[9-12]}$ As a major component of the ventral striatum, NAc extends dorsolaterally into the putamen and dorsomedially into the caudate nucleus. ${ }^{[13]}$ The NAc contains a large number of $\gamma$-aminobutyric acid (GABA)-containing medium spiny projecting neurons (\%95) and only a small populations of GABAergic and cholinergic interneurons. ${ }^{[14]}$ The activity of medium spiny neurons is regulated by glutamatergic afferents coming from the prefrontal cortex, hippocampus and amygdala, dopaminergic 
afferents from the ventral tegmental area, as well as serotonergic and noradrenergic afferents from the raphe nucleus, and the locus ceruleus, respectively. ${ }^{[15]}$ Thus, the NAc plays important roles in emotional control.

The NAc is divided into a central core surrounded by an outer shell area on its medial, ventral and ventrolateral sides. These two anatomically and functionally distinct subregions have diverse organizational patterns. ${ }^{[16]}$ While the core region projects primarily to a restricted part of the globus pallidus and the substantia nigra; the shell region projects not only to the subcommissural part of the ventral pallidum and the ventral tegmental area (VTA), but also projects to widespread areas in the hypothalamus and extended amygdala. ${ }^{[15]}$ Shell area contains substances such as calretinin, substance $\mathrm{P}$, dopamine, and serotonin, while the core area contains calbindin, encephalin and GABA A receptors. Furthermore, Fos-like immunoreactivity is higher in the shell region of the NAc. ${ }^{[17]}$

In animals displaying depression-like behavior following chronic stress exposure, glutamatergic transmission increases in the NAc. ${ }^{[18,19]}$ Intriguingly, susceptibility to depression is mediated by glutamatergic transmission from the ventral hippocampal afferents to NAc, but not from the medial prefrontal cortex or basolateral amygdala. ${ }^{[20]}$ Because in vivo optogenetic manipulations of ventral hippocampus-NAc synaptic transmission cause depressivelike behaviors, while acute enhancement of glutamatergic input from either medial prefrontal cortex or basolateral amygdala attenuates transmission and promotes resilience. Recently, inhibition of glutamate release in subregions of the hippocampus and prefrontal cortex has been shown as a promising target in the treatment of patients who do not respond to classical antidepressants. It has been demonstrated that NMDA receptor antagonist ketamine shows such an antidepressant effect by rapidly stimulating the mammalian target of rapamycin (mTOR). ${ }^{[21]}$ Ketamine reverses the deficits in synapse number and increases the levels of synaptic proteins reduced by chronic stress exposure. ${ }^{[22]}$ It has also been shown that ketamine injection significantly increases dopamine ${ }^{[2,24]}$ and blood-oxygenationlevel-dependent (BOLD) levels ${ }^{[2]}$ in the NAc after chronic stress. However, the effects of ketamine were not examined in the NAc following PS exposure. Previously, we have shown that ketamine treatment decreases c-Fos expressing cells in the medial prefrontal cortex of prenatally stressed rats. ${ }^{[2]}$ Therefore, current study aims to investigate the effects of single-dose ketamine application in the NAc of prenatally stressed rats in a subregion specific manner.

\section{Materials and Methods}

Healthy Sprague-Dawley rats obtained from the breeding colony at the Eskişehir Osmangazi University Animal Care Facility and maintained under constant temperature $\left(21^{\circ} \mathrm{C}\right)$ and light $(12: 12 \mathrm{~h} \mathrm{light} /$ dark cycle $)$ conditions. After overnight mating, pregnancy was confirmed by the sperm positivity in the vaginal smear. Pregnant rats were housed individually in transparent cages by giving free access to food and tap water. Experimental procedures were performed in accordance with protocols approved by the Institutional Animal Usage Committee (Protocol \#201/1). Dams ( $\mathrm{n}=10)$ were immobilized in close-fitting wire mesh cylinders daily for 3 hours, between E14 and E21. At postnatal day 40, male offspring from control and prenatally stressed groups $(n=20)$ received serum physiologic (CTRL+SF and PS+SF) or a single dose $(10 \mathrm{mg} / \mathrm{kg}$, i.p.) of ketamine injection (CTRL+ketamine and PS+ketamine) Animals were sacrificed two days after ketamine or SF injection. Forced swim procedure was used to stimulate neuronal activity for evaluation of the immediate gene expression. Animals were kept in an inescapable condition for $5 \mathrm{~min}$ utes, and then removed from the water, dried with towels, and sacrificed immediately via cardiac perfusion following halothane inhalation. Animals were perfused with phosphate-buffered saline (PBS) followed by 4\% paraformaldehyde in $0.1 \mathrm{M}$ phosphate buffer $(\mathrm{pH}=7.4)$. After dissection, brains were dehydrated in graded alcohols and embedded in paraffin.

The brain tissue was sectioned at $5 \mu \mathrm{m}$ thickness and every 30th section, obtained between Bregma 3.00 and 0.60 according to stereotaxic rat atlas by Paxinos and Watson, ${ }^{[2]}$ was mounted on poly-L-lysine coated slides (Figure 1). Deparaffinized and rehydrated sections were treated with $0.3 \% \mathrm{H}_{2} \mathrm{O}_{2}$ for $30 \mathrm{~min}$, washed in $\mathrm{PBS}$, and then boiled in antigen retrieval solution, containing sodium citrate $(\mathrm{pH}=6.00)$ for $5 \mathrm{~min}$ in a microwave oven. Unspecific binding was suppressed in a blocking solution for $30 \mathrm{~min}$ at room temperature. The rabbit polyclonal antibody to c-Fos (ABE457, Merck Millipore, Darmstadt, Germany) was used at 1:200 dilution. After overnight incubation at $4^{\circ} \mathrm{C}$, sections were incubated in biotinylated anti-rabbit secondary antibody (1:100, Novostain Universal Detection Kit, Novocastra Laboratories, Newcastle upon Tyne, UK) for $30 \mathrm{~min}$ at room temperature. Bound antibody was detected by streptavidin/ peroxidase complex (PK-6100, ABC Elite Kit, Vector laboratories, Burlingame, CA, USA), and diaminobenzidine (DAB) mixture as chromogen. Finally, sections were dehydrated in alcohol series, cleared in xylene, and coverslipped with permanent mounting medium. 

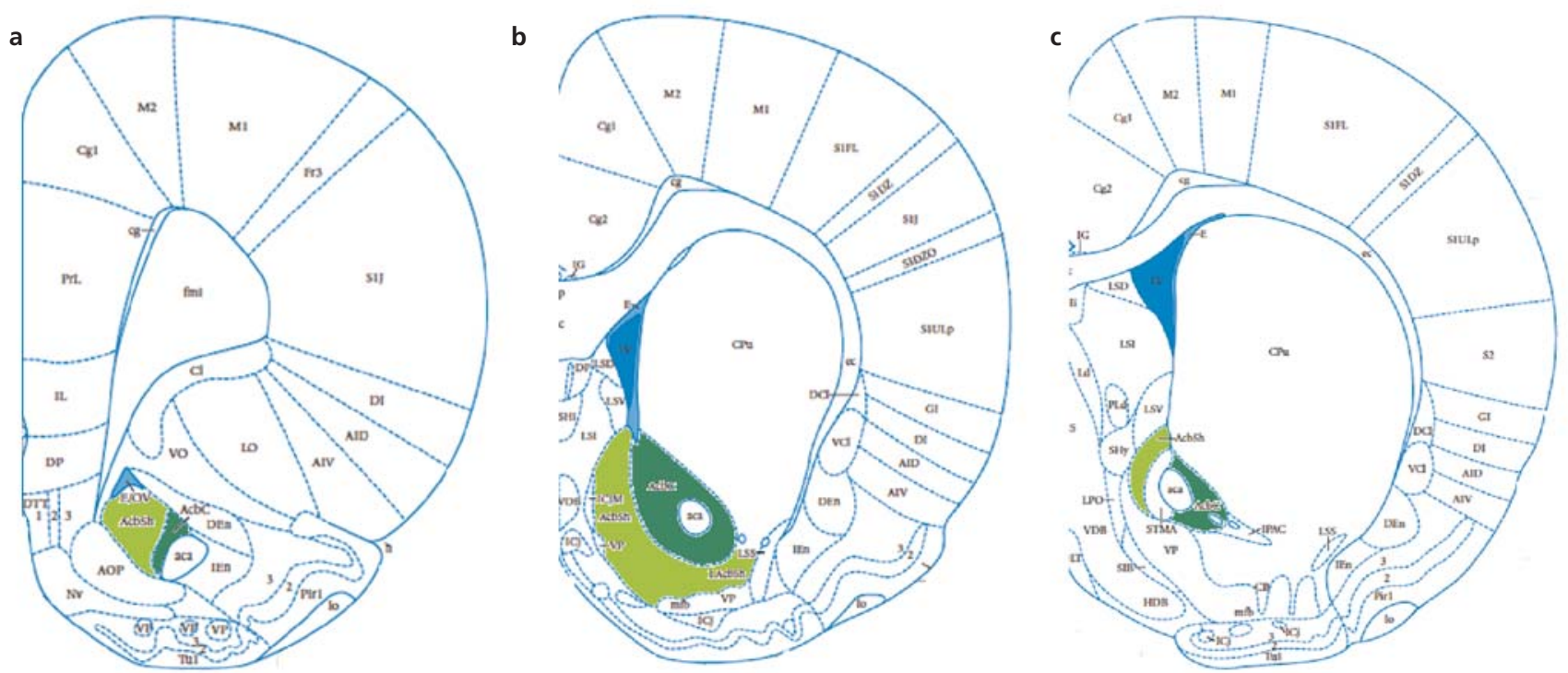

Figure 1. Representative images displaying core (dark shaded area) and shell (light shaded area) subregions of the nucleus accumbens. Images were taken from "The Rat Brain in Stereotaxic Coordinates" atlas ${ }^{[27]}$ to demonstrate our sampling region between Bregma (a) $3.00 \mathrm{~mm}$, (b) $1.80 \mathrm{~mm}$ and (c) $0.60 \mathrm{~mm}$. [Color figure can be viewed in the online issue, which is available at www. anatomy.org.tr]

The total number of c-Fos (+) nuclei was quantified using the optical fractionator probe of Stereoinvestigator system (Version 11; Microbrightfield Inc., Williston, VT, USA). Blind-coded slides were investigated by applying systematic random sampling approach in every step. Outlines of the core and shell regions were delineated and all c-Fos (+) profiles within the two-dimensional counting frames $(300 \mu \mathrm{m} \times 300 \mu \mathrm{m}$ in size) were quantified under high power magnification. Size of the grid $(400 \mu \mathrm{m} \times 400$ $\mu \mathrm{m} \times 10 \mu \mathrm{m})$ was set to sample $10-15$ sites in each section and the optical dissector height was set at $3 \mu \mathrm{m}$. The coefficient of error was calculated according to Schmitz and Hof, and values less than 0.05 were considered acceptable.

Shapiro-Wilk and Kolmogorov-Smirnov tests were used to assess normality distribution of the data. One-way ANOVA followed by Tukey's multiple comparisons test was used to compare groups. Results were considered significant at a level of $\mathrm{p}<0.05$. IBM SPSS (Statistical Package for the Social Sciences, version 21.0; IBM, Chicago, IL, USA) software was used for all the analyses.

\section{Results}

Stress-induced immediate gene expression was evaluated by using c-Fos immunohistochemistry. One-way ANOVA results displayed a significant group difference $[\mathrm{F}(3.9)=$ $11.04, p=0.0023]$ in the total number of nucleus accumbens. Total number of c-Fos (+) neurons in $\mathrm{PS}+\mathrm{SF}$ group $\left(2683 \times 10^{6}\right)$ was significantly $(\mathrm{p}<0.05)$ lower than those of $\mathrm{CTRL}+\mathrm{SF}$ group $\left(5826 \times 10^{6}\right)$, but ketamine injection significantly $(\mathrm{p}<0.01)$ enhanced the activation of cells $\left(7.923 \times 10^{6}\right)$ in PS+ketamine group (Figure 2). This activation was also significantly higher than those of CTRL group receiving single dose ketamine injection $(\mathrm{p}<0.05)$. The total number of cells in the shell area was also displayed differences among groups $[\mathrm{F}(3.9)=5.494, \mathrm{p}=0.0202]$. Total number of c-Fos $(+)$ neurons in PS+SF group (8382x $\left.10^{5}\right)$ was significantly $(\mathrm{p}<0.05)$ lower than those of CTRL+ SF group $\left(3166 \times 10^{6}\right)$, but ketamine injection significantly $(\mathrm{p}<0.01)$ enhanced the activation of cells $\left(2937 \times 10^{6}\right)$ only

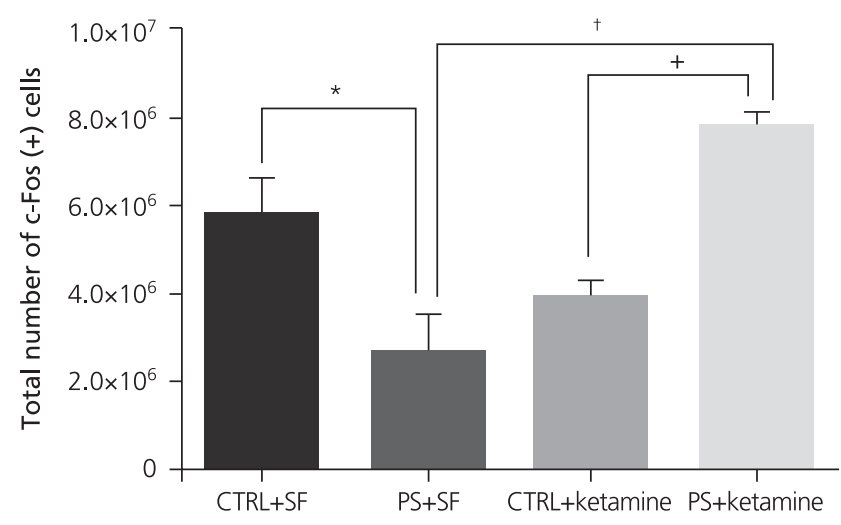

Figure 2. The total number of c-Fos (+) neurons in the nucleus accumbens. *Indicates significant $(p<0.05)$ difference between saline injected CTRL and PS groups, tindicates significant $(p<0.01)$ difference between $\mathrm{PS}+\mathrm{SF}$ and $\mathrm{PS}+$ ketamine groups. Also, there was a significant difference $(p<0.05)$ between $C T R L+k e t a m i n e$ and PS+ketamine groups indicated by + sign. Data shows the mean \pm SEM of the number of $c$-Fos expressing neurons per unit area. 
in PS+ketamine group. Therefore, the activation of cells was comparable in CTRL groups treated with either ketamine or saline injection (Figure 3).

Likewise the previous groups, activation of cells in the core area displayed a significant group difference $[\mathrm{F}(3.9)=7.438, \mathrm{p}=0.0083]$. However, in this subregion of the NAc prenatal stress exposure did not reduce the total number of c-Fos (+) cells. One-way ANOVA results showed that activation of cells in PS group was similar to CTRL groups treated with either SF or ketamine (Figure 4). Thus, group difference was due to enhancement (4986x $\left.10^{6}\right)$. in the number of activated cells in ketamine-treated PS group.

\section{Discussion}

Stress exposure causes alterations in the morphology and activity of neurons in the mesocorticolimbic structures in a region specific manner. In this study, we showed that PS decreases the number of c-Fos $(+)$ cells in NAc and a single dose ketamine treatment reverses this effect. Interestingly, the impact of prenatal stress exposure was seen only in the shell area, while ketamine treatment affected both core and shell subregions of the NAc.

Previous studies indicate that environmental factors might cause structural, functional, molecular, and epigenetic alterations in the NAc. ${ }^{[28-31]}$ Activation of the ventral hippocampus has an acute stimulatory effect on dopamine release in the shell of the NAC, while it has a suppressive effect on extracellular dopamine levels in the core subregion. ${ }^{[32]}$ Volumetric changes might be seen in the NAc of depressive patients, although inconsistent results were reported in the literature. While most of the studies showed no alterations in the volume of the NAc in patients having major depression, ${ }^{[3,34]}$ some reports displayed reduction in its volume, especially in elderly patients. ${ }^{[35]}$ On the other hand, in glutamate-based depression cases over activation of extrasynaptic NMDA receptors by glutamate causes NAc hypertrophy. ${ }^{[36]}$ In addition, in these patients, an activity reduction could be seen in the whole ventral striatum area. ${ }^{[37,38]}$ Similar to our study's results, it has been shown that PS modulates the activity of NAc by decreasing the cell proliferation ${ }^{[39]}$ and reducing the volume of NAc. ${ }^{[40]}$ Likewise, stress and depression cause phasic activation of the VTA-NAc pathway and corelease dopamine and BDNF in the NAc region. ${ }^{[4]}$ Ketamine infusion in rodents increases spontaneous activation of dopaminergic neurons in the VTA and extracellular dopamine level in the NAc. ${ }^{[2]}$ These results imply that enhanced neuronal activation seen in the current study following ketamine treatment might be caused by dopaminergic system activation.

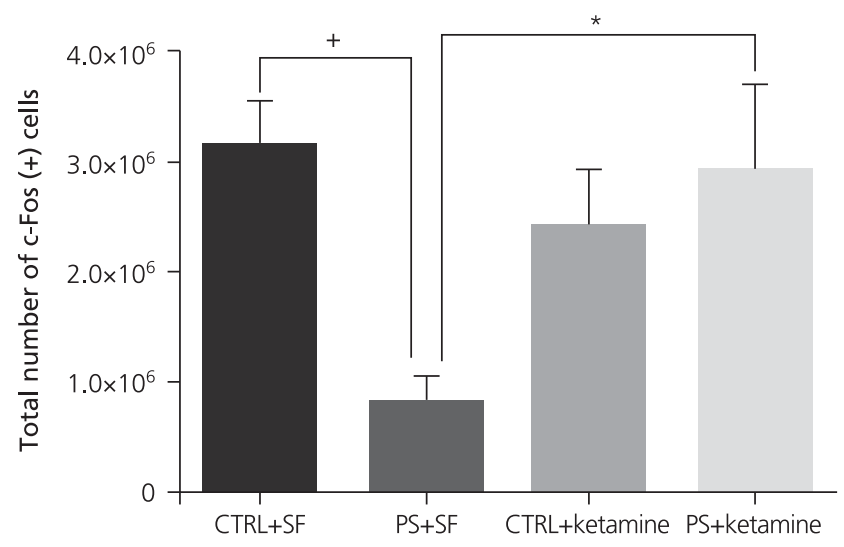

Figure 3. The total number of c-Fos (+) neurons in shell area of the nucleus accumbens. Quantitative analyses showed significant $(+p<0.05)$ differences between CRTL+SF and PS+SF and between PS+SF and PS+ketamine groups $\left({ }^{*} p<0.05\right)$. Data shows the mean \pm SEM of the number of $c$-Fos expressing neurons per unit area.

It is known that stressful events can induce gene expression by chromatin remodeling and histone modification, which then cause addiction behavior. As Schroeder et al..$^{[43]}$ pointed out, region-specific D1-receptor-regulated histone (phospho) acetylation affects gene expression and differentially regulates reward circuitry. Reus et al. ${ }^{[4]}$ showed that ketamine treatment did not affect histone deacetylase (HDAC) activity in the prefrontal cortex, hippocampus and amygdala of maternally deprived adult rats. In contrast, there is an increased HDAC activity in the nucleus accumbens of deprived rat and it has been shown that ketamine treatment was able to reverse this alteration specifically in this region.

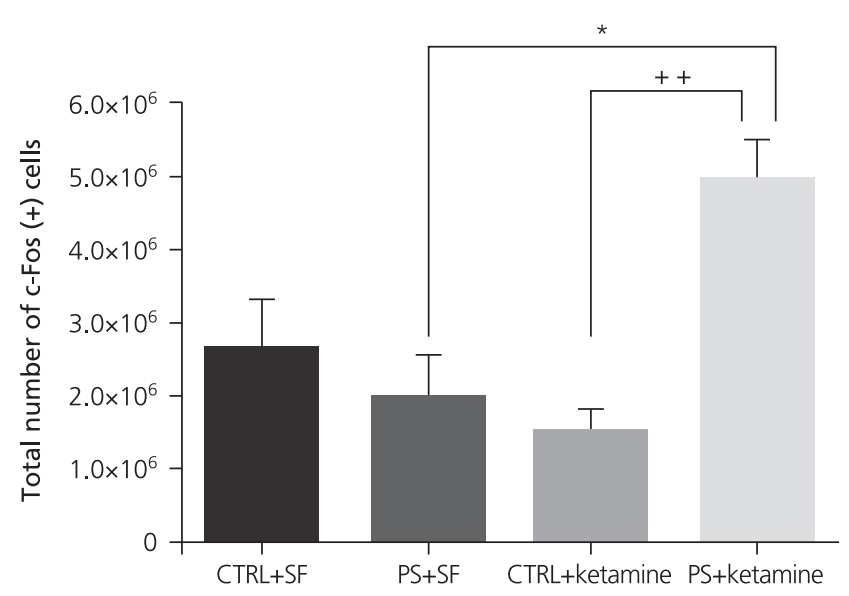

Figure 4. The total number of c-Fos (+) neurons in the core area of nucleus accumbens. Quantitative analyses showed significant $\left({ }^{*} p<0.05\right)$ differences between PS+SF and PS+ketamine group. Also there was a signifi-

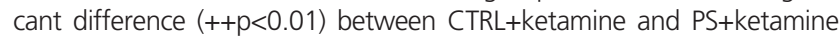
groups. Data shows the mean \pm SEM of the number of c-Fos expressing neurons per unit area. 
Various NMDA receptor antagonists have been shown to enhance dopamine levels in the NAc in a subregionspecific manner ${ }^{[45,46]}$ For example, phencyclidine (PCP) and dizocilpine (MK-801) significantly elevate extracellular dopamine levels in the shell subregion, but not cause alterations in the core subregion. Low doses of the another competitive NMDA receptor antagonist CGP 39551 failed to affect dopamine output in either region; while at higher doses it elevates the dopamine output in the shell compared to the core subregion. ${ }^{[4]}$ It seems like, the effects of NMDA receptors and dopamine dysregulation are region specific by affecting predominantly the shell subregion of the NAc. ${ }^{[48]}$ In our study, we observed that ketamine treatment enhanced the activation of cells in both shell and core regions. These differences might be related to the dose and action mechanisms of different NMDA receptor antagonists. As a matter of fact, it has been noted that ketamine acts differentially at higher or lower doses in terms of changing the basal firing rates of ventral tegmental DA neurons. ${ }^{[49]}$

\section{Conclusion}

Current clinical and animal studies report that subanesthetic dose of ketamine produces antidepressant like effect especially in treatment-resistant patients. The effects of ketamine have been mostly investigated following acute or chronic stress exposure, but its effects in prenatal stress paradigm is not well understood. Our study showed that although PS particularly reduces the activation of the cells in the shell subregion, ketamine treatment could act on both core and shell regions by affecting glutamatergic limbic information that flows from shell to core subregion of the NAc.

\section{References}

1. Fumagalli F, Molteni R, Racagni G, Riva MA. Stress during development: impact on neuroplasticity and relevance to psychopathology. Prog Neurobiol 2007;81:197-217.

2. Weinstock $M$. The long-term behavioural consequences of prenatal stress. Neurosci Biobehav Rev 2008;32:1073-86.

3. Said N, Lakehayli S, El Khachibi M, El Ouahli M, Nadifi S, Hakkou F, Tazi A. Prenatal stress induces vulnerability to nicotine addiction and alters D2 receptors' expression in the nucleus accumbens in adult rats. Neuroscience 2015;304:279-85.

4. Zhu X, Li T, Peng S, Ma X, Chen X, Zhang X. Maternal deprivation-caused behavioral abnormalities in adult rats relate to a nonmethylation-regulated D2 receptor levels in the nucleus accumbens. Behav Brain Res 2010;209:281-8.

5. Cai Q, Zhu Z, Li H, Fan X, Jia N, Bai Z, Song L, Li X, Liu J. Prenatal stress on the kinetic properties of $\mathrm{Ca} 2+$ and $\mathrm{K}+$ channels in offspring hippocampal CA3 pyramidal neurons. Life Sci 2007;80: 681-9.
6. Ulupinar E, Yucel F, Ortug G. The effects of prenatal stress on the Purkinje cell neurogenesis. Neurotoxicol Teratol 2006;28:86-94.

7. Weinstock M. Prenatal stressors in rodents: effects on behavior. Neurobiol Stress 2016;6:3-13.

8. Kofman O. The role of prenatal stress in the etiology of developmental behavioural disorders. Neurosci Biobehav Rev 2002;26:457-70.

9. Kawamura T, Chen J, Takahashi T, Ichitani Y, Nakahara D. Prenatal stress suppresses cell proliferation in the early developing brain. Neuroreport 2006;17:1515-8.

10. McClure WO, Ishtoyan A, Lyon M. Very mild stress of pregnant rats reduces volume and cell number in nucleus accumbens of adult offspring: some parallels to schizophrenia. Brain Res Dev Brain Res 2004;149:21-8.

11. Shirayama Y, Chaki S. Neurochemistry of the nucleus accumbens and its relevance to depression and antidepressant action in rodents. Curr Neuropharmacol 2006;4:277-91.

12. Baier CJ, Katunar MR, Adrover E, Pallarés ME, Antonelli MC. Gestational restraint stress and the developing dopaminergic system: an overview. Neurotox Res 2012;22:16-32.

13. Salgado S, Kaplitt MG. The nucleus accumbens: a comprehensive review. Stereotact Funct Neurosurg 2015;93:75-93.

14. Meredith GE, Pennartz CM, Groenewegen HJ. The cellular framework for chemical signalling in the nucleus accumbens. Prog Brain Res 1993;99:3-24.

15. Pennartz CM, Dolleman-Van der Weel MJ, Kitai ST, Lopes da Silva FH. Presynaptic dopamine D1 receptors attenuate excitatory and inhibitory limbic inputs to the shell region of the rat nucleus accumbens studied in vitro. J Neurophysiol 1992;67:1325-34.

16. Zahm DS, Brog JS. On the significance of subterritories in the "accumbens" part of the rat ventral striatum. Neuroscience 1992;50: $751-67$.

17. Deutch AY, Lee MC, Iadarola MJ. Regionally specific effects of atypical antipsychotic drugs on striatal Fos expression: the nucleus accumbens shell as a locus of antipsychotic action. Mol Cell Neurosci 1992;3:332-41.

18. Vialou V, Robison AJ, Laplant QC, Covington HE 3rd, Dietz DM, Ohnishi YN, Mouzon E, Rush AJ 3rd, Watts EL, Wallace DL, Iñiguez SD, Ohnishi YH, Steiner MA, Warren BL, Krishnan V, Bolaños CA, Neve RL, Ghose S, Berton O, Tamminga CA, Nestler EJ. DeltaFosB in brain reward circuits mediates resilience to stress and antidepressant responses. Nat Neurosci 2010;13:745-52.

19. Lim BK, Huang KW, Grueter BA, Rothwell PE, Malenka RC. Anhedonia requires MC4R-mediated synaptic adaptations in nucleus accumbens. Nature 2012;487:183-9.

20. Bagot RC, Parise EM, Peña CJ, Zhang HX, Maze I, Chaudhury D, Persaud B, Cachope R, Bolaños-Guzmán CA, Cheer JF, Deisseroth K, Han MH, Nestler EJ. Ventral hippocampal afferents to the nucleus accumbens regulate susceptibility to depression. Nat Commun 2015;6:7062.

21. Browne CA, Lucki I. Antidepressant effects of ketamine: mechanisms underlying fast-acting novel antidepressants. Front Pharmacol 2013; 4:161.

22. Duman RS, Li N, Liu RJ, Duric V, Aghajanian G. Signaling pathways underlying the rapid antidepressant actions of ketamine. Neuropharmacology 2012;62:35-41.

23. Wu R, Zhang H, Xue W, Zou Z, Lu C, Xia B, Wang W, Chen G. Transgenerational impairment of hippocampal Akt-mTOR signaling and behavioral deficits in the offspring of mice that experience postpartum depression-like illness. Prog Neuropsychopharmacol Biol Psychiatry 2017;73:11-8. 
24. Kokkinou M, Ashok AH, Howes OD. The effects of ketamine on dopaminergic function: meta-analysis and review of the implications for neuropsychiatric disorders. Mol Psychiatry 2017.

25. Masuzawa M, Nakao S, Miyamoto E, Yamada M, Murao K, Nishi K, Shingu K. Pentobarbital inhibits ketamine-induced dopamine release in the rat nucleus accumbens: a microdialysis study. Anesth Analg 2003;96:148-52.

26. Polat Çorumlu E, Aydın OÖ, Gülhan Aydın E, Ulupınar E. Effects of single-dose ketamine infusion on behavioral parameters and neuronal activation in the medial prefrontal cortex of juvenile rats exposed to prenatal stress. Anatomy 2015;9:142-50.

27. Paxinos G, Watson C. The rat brain in stereotaxic coordinates. 2nd ed., San Diego (CA): Academic Press; 1986.

28. Peleg-Raibstein D, Feldon J. Effects of dorsal and ventral hippocampal NMDA stimulation on nucleus accumbens core and shell dopamine release. Neuropharmacology 2006;51:947-57.

29. Robinson TE, Kolb B. Structural plasticity associated with exposure to drugs of abuse. Neuropharmacology 2004;47:33-46.

30. Russo SJ, Dietz DM, Dumitriu D, Morrison JH, Malenka RC, Nestler EJ. The addicted synapse: mechanisms of synaptic and structural plasticity in nucleus accumbens. Trends Neurosci 2010;33:267-76.

31. Schmidt HD, Pierce RC. Cocaine-induced neuroadaptations in glutamate transmission: potential therapeutic targets for craving and addiction. Ann N Y Acad Sci 2010;1187:35-75.

32. Solinas M, Thiriet N, El Rawas R, Lardeux V, Jaber M. Environmental enrichment during early stages of life reduces the behavioral, neurochemical, and molecular effects of cocaine. Neuropsychopharmacology 2009;34:1102-11.

33. Bremner JD, Narayan M, Anderson ER, Staib LH, Miller HL, Charney DS. Hippocampal volume reduction in major depression. Am J Psychiatry 2000;157:115-8.

34. Hannestad J, Taylor WD, McQuoid DR, Payne ME, Krishnan KR, Steffens DC, Macfall JR. White matter lesion volumes and caudate volumes in late-life depression. Int J Geriatr Psychiatry 2006;21: 1193-8.

35. Russo SJ, Nestler EJ. The brain reward circuitry in mood disorders. Nat Rev Neurosci 2013;14:609-25.

36. Krishnan KR, McDonald WM, Escalona PR, Doraiswamy PM, Na C, Husain MM, Figiel GS, Boyko OB, Ellinwood EH, Nemeroff $\mathrm{CB}$. Magnetic resonance imaging of the caudate nuclei in depression. Preliminary observations. Arch Gen Psychiatry 1992;49:553-7.

37. Abdallah CG, Jackowski A, Salas R, Gupta S, Sato JR, Mao X, Coplan JD, Shungu DC, Mathew SJ. The nucleus accumbens and ketamine treatment in major depressive disorder. 2017;42:1739-46.

38. Drevets WC, Videen TO, Price JL, Preskorn SH, Carmichael ST, Raichle ME. A functional anatomical study of unipolar depression. J Neurosci 1992;12:3628-41.
39. Kawamura T, Chen J, Takahashi T, Ichitani Y, Nakahara D. Prenatal stress suppresses cell proliferation in the early developing brain. Neuroreport 2006;17:1515-8.

40. McClure WO, Ishtoyan A, Lyon M. Very mild stress of pregnant rats reduces volume and cell number in nucleus accumbens of adult offspring: some parallels to schizophrenia. Brain Res Dev Brain Res 2004;149:21-8.

41. Walsh JJ, Friedman AK, Sun H, Heller EA, Ku SM, Juarez B, Burnham VL, Mazei-Robison MS, Ferguson D, Golden SA, Koo JW, Chaudhury D, Christoffel DJ, Pomeranz L, Friedman JM, Russo SJ, Nestler EJ, Han MH. Stress and CRF gate neural activation of BDNF in the mesolimbic reward pathway. Nat Neurosci 2014;17:27-9.

42. Witkin JM, Monn JA, Schoepp DD, Li X, Overshiner C, Mitchell SN, Carter G, Johnson B, Rasmussen K, Rorick-Kehn LM. The rapidly acting antidepressant ketamine and the $\mathrm{mGlu} 2 / 3$ receptor antagonist LY341495 rapidly engage dopaminergic mood circuits. J Pharmacol Exp Ther 2016;358:71-82.

43. Schroeder FA, Penta KL, Matevossian A, Jones SR, Konradi C, Tapper AR, Akbarian S. Drug-induced activation of dopamine D(1) receptor signaling and inhibition of class I/II histone deacetylase induce chromatin remodeling in reward circuitry and modulate cocaine-related behaviors. Neuropsychopharmacology 2008;33: 2981-92.

44. Réus GZ, Abelaira HM, dos Santos MA, Carlessi AS, Tomaz DB, Neotti MV, Liranço JL, Gubert C, Barth M, Kapczinski F, Quevedo $\mathrm{J}$. Ketamine and imipramine in the nucleus accumbens regulate histone deacetylation induced by maternal deprivation and are critical for associated behaviors. Behav Brain Res 2013;256:451-6.

45. Svensson TH. Dysfunctional brain dopamine systems induced by psychotomimetic NMDA-receptor antagonists and the effects of antipsychotic drugs. Brain Res Brain Res Rev 2000;31:320-9.

46. Peleg-Raibstein D, Feldon J. Effects of dorsal and ventral hippocampal NMDA stimulation on nucleus accumbens core and shell dopamine release. Neuropharmacology 2006;57:947-57.

47. Marcus MM, Mathé JM, Nomikos GG, Svensson TH. Effects of competitive and non-competitive NMDA receptor antagonists on dopamine output in the shell and core subdivisions of the nucleus accumbens. Neuropharmacology 2001;40:482-90.

48. Pouvreau T, Tagliabue E, Usun Y, Eybrard S, Meyer F, Louilot A. Neonatal prefrontal inactivation results in reversed dopaminergic responses in the shell subregion of the nucleus accumbens to NMDA antagonists. ACS Chem Neurosci 2016;7:964-71.

49. Irifune M, Fukuda T, Nomoto M, Sato T, Kamata Y, Nishikawa T, Mietani W, Yokoyama K, Sugiyama K, Kawahara M. Effects of ketamine on dopamine metabolism during anesthesia in discrete brain regions in mice: comparison with the effects during the recovery and subanesthetic phases. Brain Res 1997;763:281-4.

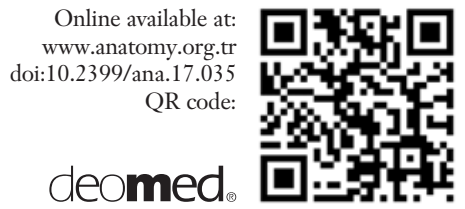

Correspondence to: Emel Ulupınar, MD, PhD

Department of Anatomy, Faculty of Medicine,

Osmangazi University, Eskisehir, Turkey

Phone: +90 (222) 2393772

e-mail: eulupi@ogu.edu.tr

Conflict of interest statement: No conflicts declared.

This is an open access article distributed under the terms of the Creative Commons Attribution-NonCommercial-NoDerivs 3.0 Unported (CC BY-NCND3.0) Licence (http://creativecommons.org/licenses/by-nc-nd/3.0/) which permits unrestricted noncommercial use, distribution, and reproduction in any medium, provided the original work is properly cited. Please cite this article as: Polat Çorumlu E, Aydın OÖ, Ulupınar E. Single dose ketamine injection affects activation of cells in the nucleus accumbens of prenatally stressed rats. Anatomy 2017;11(3):115-120. 